\title{
Análise morfométrica da transição esôfago-gástrica de eqüinos submetidos a diferentes manejos alimentares e atividade física
}

\author{
Morphometric analysis of the esophagus-gastric transition in horse submitted to different feeding \\ management and physical activities
}

\author{
Priscilla Teixeira de Barros Moraes ${ }^{\mathrm{I}}$ Luís Claúdio Lopes Correia da Silva ${ }^{\mathrm{II}}$ Pedro Primo Bombonato ${ }^{\mathrm{II}}$ \\ Francisco Javier Hernadez Blazquez ${ }^{\mathrm{II}}$ Eduardo Maurício Mendes de Lima ${ }^{\mathrm{II}}{ }^{*}$
}

\section{RESUMO}

O objetivo deste trabalho foi identificar se diferentes tipos de manejo físico e alimentar determinaram mudanças adaptativas na morfometria da região de transição esôfagogástrica (TEG) em eqüinos. Foram utilizados 15 conjuntos de animais adultos com raça, sexo e idade não identificados, divididos em três grupos de acordo com a dieta e a atividade física: grupo I - composto por cinco conjuntos da TEG de eqüinos em treinamento intensivo e alimentados principalmente à base de concentrado; grupo II - com cinco conjuntos da TEG de eqüinos que não desempenhavam atividade física intensa e eram alimentados principalmente à base de concentrado, e o grupo III - composto por cinco conjuntos da TEG de eqüinos mantidos a pasto e que não desempenhavam atividade física intensa. A região de transição esôfago-gástrica teve a estrutura do seu epitélio avaliada morfometricamente, onde foram feitas mensurações para identificar a espessura do epitélio estratificado pavimentoso queratinizado. A espessura do grupo I teve como média $122,3 \mu \mathrm{m}$, do grupo II foi de $173,4 \mu \mathrm{m}$ e do grupo III foi de 281,7 $\mu \mathrm{m}$. Os resultados encontrados para a espessura do epitélio estratificado pavimentoso queratinizado dos eqüinos mostraram a existência de diferenças estatisticamente significativas dos eqüinos do grupo I, quando comparados aos eqüinos do grupo III.

Palavras-chave: transição esôfago-gástrica, exercício físico, dieta, eqüinos.

\section{ABSTRACT}

The objective of this research was to identify if different kind of physical and alimentary management determine adaptative changes in morphometry of the esophagus-gastric transition epithelium. 15 sets comprehending the esophagus-gastric transition region (TEG) was used in adult horses considering undefined breed, gender and age divided in three groups according to diet and physical activity: group $I$ - Five sets (TEG) of horses in intensive training fed with commercial ration; group II - Five sets (TEG) of horses which did not develop any intensive physical activity and fed by commercial ration; group III - Five sets (TEG) of horses kept in the grass without any extra feeding which did not develop any intensive physical activity. The esophagus-gastric transition region had its epithelium structure evaluated morphometrically where measurements were done to identify the thickness of the stratified squamous keratinized epithelium. The thickness of

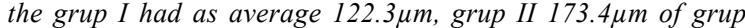
III $281.7 \mu \mathrm{m}$. Results of stratified squamous keratinized epithelium thickness have shown the existence of statistically significant differences of group I when compared to group III.

Key words: esophagus-gastric transition, physical exercise, diet, horses.

\section{INTRODUÇÃO}

A estrutura morfológica muito peculiar evidenciada tanto no esôfago como no estômago de eqüinos é um fator prevalente e clinicamente relevante na rotina clínica dessa espécie. Em relação a estas estruturas, se faz necessário o conhecimento morfológico e a análise de possíveis alterações adaptativas, em especial aquelas dispostas na região de transição esôfago-gástrica, pois fatores ambientais e de manejo podem provocar lesões nessa região em eqüinos. Os fatores intrínsecos que predispõem a região a sofrer lesões tomam como base o arranjo

\footnotetext{
IPrograma de Pós-graduação em Anatomia dos Animais Domésticos e Silvestres, Faculdade de Medicina Veterinária e Zootecnia (FMVZ), Universidade de São Paulo (USP), São Paulo, SP, Brasil.

IIDepartamento de Cirurgia, FMVZ/USP, São Paulo, SP, Brasil.

IIIFaculdade de Agronomia e Medicina Veterinária (FAV), Universidade de Brasília (UNB), Instituto Central de Ciências Ala Sul, Campus Universitário Darcy Ribeiro, CP 4508, 70910-970, Brasília, DF, Brasil. E-mail: limaemm@unb.br.*Autor para correspondência.
} 
morfológico dos órgãos dispostos nessa região, o tipo de alimento ingerido, a freqüência de oferta desses alimentos, o jejum prolongado (SWEENEY, 1992), o estresse, a administração de antiinflamatórios nãoesteróides e a intensidade de exercícios físicos a que esses eqüinos são submetidos.

O esôfago é revestido internamente por um epitélio estratificado pavimentoso, desprovido de glândulas, salvo na junção faringo-esofágica. De uma forma genérica, BANKS (1992), DYCE et al. (2004) e FRANDSON et al. (2005) consideram que esee epitélio possui um grau de queratinização variável entre as espécies, de acordo com a qualidade de sua alimentação. Na espécie eqüina, o limite entre os epitélios esofágico e gástrico é nítido e pode ser deslocado para qualquer lado do cárdia (DYCE et al., 2004). Assim quando comparado a outras espécies, evidencia-se uma superfície epitelial mais espessa e a ausência de glândulas, exceto na região próxima à laringe (SLOCOMBE et al.,1982).

O estômago do eqüino é coberto por uma mucosa aglandular ou esofágica, que ocupa o fundo e a parte do corpo do estômago, sendo desta forma semelhante estruturalmente à mucosa do esôfago, e outra glandular, que se estende ao longo do cárdia, parte do corpo e ainda região pilórica, possuindo células responsáveis pela produção das secreções gástricas (GETTY, 1986, DARGATZ \& BROWN, 1997). A transição do epitélio estratificado pavimentoso da região esofágica no eqüino estende-se por toda a região aglandular, sendo que o início da região de glândulas cárdicas demarca o epitélio glandular no estômago (DELLMANN \& BROWN, 1983). Essa transição é observada macroscopicamente pela presença da margem pregueada (FRANDSON et al., 2005).

Para DELLMAN \& BROWN (1983) e BANKS (1992), na região de transição esôfagogástrica, o esôfago possui características morfológicas variáveis de acordo com a disposição e os arranjos das camadas de revestimento. Já FRANDSON et al. (2005) consideram que a camada mais interna consiste em epitélio escamoso estratificado da boca até a parte glandular do estômago, sendo que subjacente a este verifica-se a presença de tecido conjuntivo e uma camada de músculo liso variavelmente presente, bem como a presença da camada muscular, constituída de músculos estriado esquelético e liso que se cruzam entre si. DYCE et al. (2004) comentam ainda que o epitélio superficial, em geral, é escamoso estratificado, com grau de queratinização variando entre as espécies de acordo com a aspereza da dieta habitual, mostrando nitidamente o limite dos epitélios esofágicos e gástrico, podendo o mesmo ser deslocado para qualquer lado do cárdia.
O objetivo da presente investigação foi identificar se diferentes tipos de manejo físico e alimentar determinaram mudanças adaptativas no arranjo morfológico da região de transição esôfagogástrica. Para tanto, avaliou-se morfometricamente a mucosa da região de transição esôfago-gástrica, especificamente a espessura do epitélio estratificado pavimentoso queratinizado, desprezando a lâmina própria e muscular da mucosa.

\section{MATERIAL E MÉTODOS}

Foram utilizados 15 conjuntos compreendendo a região de transição esôfago-gástrica (TEG) de eqüinos adultos com raça, sexo e idade não identificados. A coleta destes conjuntos foi realizada por meio da divisão em grupos, que foram estabelecidos de acordo com o tipo de dieta e a atividade física desenvolvida. Os conjuntos do grupo I foram provenientes de cinco animais em treinamento intensivo alimentados principalmente à base de concentrado; o grupo II foi composto por cinco conjuntos de animais que não desempenhavam atividade física intensa e foram alimentados principalmente à base de concentrado. Por fim, o grupo III foi composto por cinco conjuntos de animais mantidos a pasto, que não receberam suplementação alimentar com concentrado e não desempenhavam atividade física intensa.

Os animais de cada grupo tiveram seus conjuntos da região de TEG retirados imediatamente após eutanásia, abate ou morte natural, na dependência da proveniência, os quais foram então lavados em solução salina $0,9 \%$, preservados e refrigerados. Posteriormente, esses conjuntos foram lavados com água corrente e então submetidos à fixação em solução aquosa a 10\% de formaldeído, por 48 horas.

Após a fixação, obtiveram-se fragmentos da região de TEG de aproximadamente $1 \mathrm{~cm}^{2}$, os quais foram submetidos à técnica histológica convencional e corados com Hematoxilina-Eosina. Em seguida, confeccionaram-se lâminas histológicas desta região para que tivessem a estrutura do seu epitélio avaliada morfometricamente. Para tanto, se empregou programa específico de morfometria KS400 Zeiss ${ }^{\mathrm{a}}$.

Destas imagens foram feitas mensurações relativas à espessura do epitélio estratificado pavimentoso queratinizado mediante a aferição de duas medidas, para cada fragmento mensurado (Tabela 1). Diante dos valores obtidos nas avaliações microscópicas das espessuras do epitélio estratificado pavimentoso queratinizado da região de TEG dos eqüinos dos três grupos, com nível de significância de 
Tabela 1 - Valores absolutos das mensurações (medida 1, medida 2 e média) das espessuras $(\mu \mathrm{m})$ do epitélio estratificado pavimentoso queratinizado da mucosa da região de transição esôfago-gástrica dos eqüinos (A1, A2, A3, A4 e A5) submetidos a diferentes manejos alimentares e à atividade física de cada um dos três grupos (GI, GII, GIII), São Paulo, SP, 2007.

\begin{tabular}{cccc}
\hline Animal & Medida 1 & Medida 2 & Média \\
\hline A1GI & 119,2 & 145,7 & 132,5 \\
A2GI & 136,7 & 126,8 & 131,7 \\
A3GI & 108,1 & 104,4 & 106,2 \\
A4GI & 122,6 & 119,3 & 121,0 \\
A5GI & 118,5 & 122,1 & 120,3 \\
A1GII & 259,8 & 220,3 & 240,0 \\
A2GII & 132,8 & 113,7 & 123,3 \\
A3GII & 146,1 & 211,2 & 178,7 \\
A4GII & 140,5 & 150,5 & 145,5 \\
A5GII & 192,3 & 167,0 & 179,7 \\
A1GIII & 389,4 & 370,7 & 380,0 \\
A2GIII & 213,1 & 196,6 & 204,9 \\
A3GIII & 284,4 & 390,2 & 337,3 \\
A4GIII & 316,8 & 323,7 & 320,2 \\
A5GIII & 142,4 & 189,5 & 165,9 \\
\hline
\end{tabular}

0,05 , verificou-se a existência ou não de diferenças estatisticamente significativas a partir do teste de Kruskal-Wallis.

Também aplicou-se o teste de U de MannWhitney para os valores dos diferentes grupos, combinados dois a dois, com nível de significância de 5\%, em uma prova bilateral, a fim de avaliar a existência ou não de diferenças estatisticamente significativas. Este teste foi aplicado de acordo com os resultados obtidos entre as diferenças nas medidas microscópicas da espessura do epitélio estratificado pavimentoso queratinizado da região de TEG dos eqüinos dos três grupos quando aplicado o teste de Kruskal-Wallis.

\section{RESULTADOS E DISCUSSÃO}

Assim como descrito por DELLMANN \& BROWN (1983), BANKS (1992) e JUNQUEIRA \& CARNEIRO (1995), evidenciou-se, na região de transição esôfago-gástrica (TEG) dos animais investigados, a presença de um epitélio estratificado pavimentoso queratinizado, epitélio estratificado pavimentoso não-queratinizado, lâmina própria, camada muscular da mucosa, submucosa, camadas musculares interna e externa e ainda uma serosa. Foi observado que o epitélio esofágico é contínuo com o do estômago e sua mudança é nítida na região delimitada pela margem pregueada, a exemplo do citado por DARGATZ \& BROWN (1997).
DELLMANN \& BROWN (1983) citaram a presença de glândulas esofágicas na camada submucosa do epitélio que se estenderam até o estômago. Já WHEATER et al. (1993) relataram a presença de uma zona de glândulas na região cárdica, secretora de muco ao redor da entrada do estômago, fato que foi também evidenciada neste trabalho.

A espessura do epitélio gástrico foi anteriormente avaliada em eqüinos por MURRAY et al. (2001), adicionalmente, nos animais investigados neste trabalho, foi realizada a mensuração da espessura do epitélio estratificado pavimentoso queratinizado de animais que estiveram submetidos a diferentes manejos alimentares e de exercícios físicos.

Frente aos diferentes grupos de eqüinos agora estudados em relação às mensurações da espessura do epitélio estratificado pavimentoso queratinizado, observou-se que os valores encontrados para os animais do grupo III foram mais elevados se comparados com os valores dos animais do do grupo II, que, por sua vez foram maiores que os valores dos animais do grupo I. Isso sugeriu que pode haver uma relação entre a atividade física, a dieta e o comportamento do epitélio desta região (Tabela 1).

Com base nestes resultados, empregou-se análise estatística para confirmar os dados obtidos a partir das médias da espessura microscópica do epitélio estratificado pavimentoso queratinizado da região de TEG, por meiodo teste Kruskal-Wallis, com nível de significância 0,05 . Nos eqüinos dos três grupos observou que houve diferenças estatisticamente significativas $(\mathrm{P}=0,0077)$.

Em virtude das diferenças estatisticamente significativas para os valores dos diferentes grupos encontrados a partir da mensuração microscópica da espessura do epitélio estratificado pavimentoso queratinizado da região de TEG, estas diferenças foram avaliadas o teste de U de Mann-Whitney foi aplicado, combinados dois a dois, com nível de significância de 5\%, em uma prova bilateral. Assim, foi possível observar a existência de diferenças estatisticamente significativas entre os eqüinos dos grupos I e III. Foi identificada diferença estatisticamente significativa entre os eqüinos dos grupos I e II, e entre os dos grupos II e III.

A espessura do epitélio estratificado pavimentoso queratinizado da mucosa dos eqüinos sofre influência tanto da dieta quanto da atividade física. Este resultado difere do trabalho de MURRAY (2001), que 
mensurou a espessura de todas as camadas do epitélio gástrico, além da extensão capilar no epitélio e da espessura da lâmina própria do eqüino, e encontrou animais com mucosa intacta, mas com uma variação na espessura do epitélio gástrico e sem a presença de infiltrado inflamatório na lâmina própria. Sobretudo MURRAY (2001) não fez menção à interferência de qualquer fator externo que interfere nesta modificação. Nos animais estudados na presente pesquisa, foram considerados ainda as possíveis interferências da dieta e atividade física atuando sobre a espessura dessa mucosa .

\section{CONCLUSÃO}

A espessura microscópica do epitélio estratificado pavimentoso queratinizado da região de transição esôfago-gástrica dos eqüinos mantidos a pasto sem suplementação alimentar e que não desempenhavam atividade física, é maior do que a de eqüinos alimentados a base de concentrados e mantidos em treinamento. Isso demonstra que há correlação positiva entre alimentação e espessura do epitélio desta região.

\section{FONTES DE AQUISIÇÃO}

asistema de análise de imagem da marca Carl Zeiss ${ }^{\circledR}$, modelo KS400.

\section{COMITÊ DE ÉTICA E BEM-ESTAR ANIMAL}

Projeto aprovado sob número 614/2005 pela Comissão de Bioética da Faculdade de Medicina Veterinária e Zootecnia da Universidade de São Paulo.

\section{REFERÊNCIAS}

BANKS, B.I. Sistema digestivo I - Canal alimentar. In: Histologia veterinária aplicada. 2.ed. São Paulo: Manole, 1992. Cap.8, p.437-450.

DARGATZ, J.L.T.; BROWN, C.M. Equine endoscopy. 2.ed. Missouri: Mosby-Year Book, 1997. 252p.

DELLMANN, H.D.; BROWN, E.M. Sistema digestivo. In: Histologia veterinária. Rio de Janeiro: Guanabara

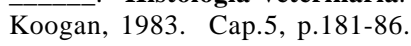

DYCE, K.M. et al. Tratado de anatomia veterinária. 5.ed. Rio de Janeiro: Guanabara Koogan, 2004. 813p.

FRANDSON, R.D. et al. Anatomia e fisiologia dos animais de fazenda. 6.ed. Rio de Janeiro: Guanabara Koogan, 2005. 454p.

GETTY, R. Sistema digestivo do eqüino. In: Sisson/ Grossman - anatomia dos animais domésticos. Rio de Janeiro: Guanabara Koogan, 1986. Cap.18, p.444-449.

JUNQUEIRA, L.C.; CARNEIRO, J. Histologia básica. In:_____ O tubo digestivo. Rio de Janeiro: Guanabara Koogan, 1995. Cap.11, p.246-254.

MURRAY, J.M. et al. Histological characteristics of induced acute peptic injury in equine gastric squamous epithelium. Equine Veterinary Journal, v.33, n.6, p.554-560, 2001.

SLOCOMBE, R.F. et al. A quantitative ultrastrutural anatomy of esophagus in differents regions in the horse: efects of alternate methods of tissue processing. American Journal of Veterinary Research, v.43, n.7, p.1137-1142, 1982.

SWEENEY, H. Gastric ulceration syndrome in foals. In Practice, v.14, p.261-268, 1992.

WHEATER, P.R. et al. Histologia funcional. In: Trato gastrointestinal. 3.ed. Rio de Janeiro: Guanabara Koogan, 1993. Cap.14, 407p. 